Case Report

\title{
Impact of Operating and Financial Expenses on Sales Revenue: The Case of Fauji Fertilizer Company Limited
}

\author{
Waqar Khalid", Saifullah Khan ${ }^{2}$ \\ ${ }^{1}$ School of Economics, Quaid-I-Azam University, Islamabad, Pakistan \\ ${ }^{2}$ Department of Management Sciences, University of Swabi, Khyber Pakhtun Khwa, Pakistan
}

Email address:

waqarkhalidicp@yahoo.com (W. Khalid), saifullahk014@gmail.com (S. Khan)

\section{To cite this article:}

Waqar Khalid, Saifullah Khan. Impact of Operating and Financial Expenses on Sales Revenue: The Case of Fauji Fertilizer Company Limited. International Journal of Business and Economics Research. Vol. 6, No. 3, 2017, pp. 40-47. doi: 10.11648/j.ijber.20170603.12

Received: May 18, 2017; Accepted: May 31, 2017; Published: July 5, 2017

\begin{abstract}
This paper is the first attempt to study the impact of operating and financial expenses on sales revenue of the Fauji Fertilizer Company Limited in Pakistan and to seek the nature as well as the strength of the relationship between sales and these expenses. The time series data for fourteen years covering 2002-2015 used were analyzed by using the Ordinary Least Square technique and a multiple regression model. These were supplemented with the elasticity and causality tests. The major findings established that there is a substantial relationship between operating expenses and sales revenue of the company, however; the relationship between financial expenses and sales revenue is not so strong comparatively. The results also confirmed that there is a significant increase in the sales revenue of the company caused by a unit change in operating expenses. It was suggested that the company should make aware the customers through advertising and general publicity on the uses and benefits of their multi-products produced. The more increase in expenses on operational aspects over the financial expenses was recommended in the future for the company in this study.
\end{abstract}

Keywords: Operating, Financial Expenses, Sales Revenue, FFC, Advertising, Multi-Products

\section{Introduction}

The basic goal of any organization, whether it is a national or a multinational organization, is to get maximum profit in an attempt to persuade the shareholder's needs or stakeholder's asset maximization as revealed by [14]. In addition, there are some other sub-objectives of the organization, for instance, the employee satisfaction, customer service, maintain financing, increasing market share, brand loyalty, being a marketplace leader or being communally responsible. No matter what the target might be, the more the turnover volume or value added, the greater and the organization will be with regard to objective recognition [12].

Even though, advertising which is one of the major fractions of administrative and distribution cost has been recognized as the center of success for nearly all competent companies [2]. The administrative and distribution outlays, typically known as the operating or ongoing expenses, are the costs (excluding cost of produce sold) that business firms incur in its daily operations but are not directly linked with the production process. These expenses include the product transportation, sale promotion with advertising, warehousing costs, establishment, salaries and wages, utilities, depreciation, transportation plus travel, and so on. Activities, for example, sales staff, occupying construction space, or running advertisements are whole the operating expenses [3]. It has an effect on the sales revenue as without usual operation the company is neither capable to make revenue. Specifically, the operating expenses have a positive impact on the sales revenue of a company as if we broaden the operating expenses; eventually we expand the marketing, administration, and selling and distribution expenditures, leading to the increase in value added in a result.

Besides the operating expenses, the second major part of the company expenses is the finance charges. The financial charges is the cost of Mark up on short period loans as well as long period financing, interest payments, bank charges, exchange gain or loss on debts, etc. It is the amount paid by the 
particular company on borrowing of money to construct or procure of assets, or it is an outflow used for securing company project arrangement.

Theoretically, the finance charges are very crucial in a company expense for the reason that we paid mark-up in the credits, the loans taken for the new business scheme will extend our production capability, expansion in plant, advancement in technology, research and development, and bringing new machinery into the company, yields the higher value added.

In this research paper, we have taken the Fauji Fertilizer Company Limited (FFC), a public limited company; because it remained continuously in the list of top 25 best performing companies of the Karachi Stock Exchange (KSE) for the last 14 years. This company was awarded the first and second position in the years 1997 and 1998 in the KSE market, respectively. In recent times, this company was in the top position among the list of top 25 companies in the financial year 2014-15 [15].

The elementary activity of this company is manufacturing, purchasing of fertilizers, urea production, energy generation, banking operations, food processing, and other manufacturing, etc. The company is now the leading manufacturer of urea in Pakistan with the total urea production ability of above 2 million tons annually plus has provided 54 million tons to the farming population since its foundation [15]. Furthermore, the number of employees in this company is more than 5 thousand, which is a large contribution to the country employment. In the year 2016, this company pays Rs. 45 billion as a tax payment to the federal government. Also, the FFC invests a lot of funds in other activities, for example, education, charity, flood rehabilitation, and so on.

The basic vision of the company has been to maintain its top position in the list of the PSX forever, and to become a leading countrywide enterprise with international aspirations. However, the attaining of such targets relies totally on the availability of sufficient finance in order to ensure the variable costs of the company. Unfortunately, there is no such a study in Pakistan, which analyzes the impact of operating and financial expenses on the sales revenue of the FFC in particular and for any company in general. Additionally, the existing literature on the issue is very limited and the available studies are not more relevant as they do not consider the major fractions of the company's expenses.

The existing studies such as [2], [13], and so on, focuses only on the impact of advertising on the sales volume for different companies like bottling, brewery, etc. and have ignored the financial effects of the companies on the sales volume. Besides, the other research studies are outdated and are not more significant.

Hence, this paper is an attempt to fill the gap in the literature and to examine the impact of operating and financial expenses on the sales volume of the selected company in an attempt to devise some policy steps to reach the company goals. As per the best of my knowledge, this study is the first attempt to cover the huge research gap in the literature that was recognized as there is no such kind of a theoretical as well as an empirical study done before for this company in Pakistan in the last decade.

(a) Objectives of the Study

Following are the main objectives of this research study.

(1) To identify the major expenses incurred by the company for increasing its sales in order to establish a prominent position in the market among the competent rivals.

(2) To estimate the impact of administrative (and distribution) expanses and financial cost on the sales volume of a company in a setup of time series.

(3) To measure the elasticity values for the different sets of variables.

(4) To find the casual relationship between any two variables in the whole system.

(b) Research Questions

Following are the two major research questions that we are going to address in this research work.

(1) What impact do operating expenses have on sales of the Fauji Fertilizer Company Limited?

(2) What impact does financial cost has on sales of the Fauji Fertilizer Company Limited?

The remaining paper is structured as follows. Section 2 presents the existing literature on the study. Section 3 gives a detailed description of the dataset. Section 4 deals with the methodology and estimation procedure. The model results are given in section 5. The last section of the paper, which is section 6, summarizes the whole study with some policy recommendations.

\section{Literature Review}

Over the last three to four decades, a higher number of research studies have been carried out by many scholars that emphasize the impact of advertising on sales volume or performance of different companies in different economies. At the beginning, Holtje (1978) as cited by Ewuola (2004) showed that recent advertising operation initiated at some point in the American Colonial time subsequent to the days the colonial reporters (newspapers) were uncomplaining advertised in a straight line from public plus institutions that required their services. A few home post officers were too supporting in this respect by performing as agents for these newspapers.

The economic effects of advertising have been an immense debated topic in the disciplines of Economics, Business Administration and Management Sciences and studied extensively over the last half century. For instance, [18] has studied the relationship between advertisement expenditures and aggregate demand and found that advertisement expenditures have a positive and significant relation with aggregate demand. Conversely, [4] examined the association between advertising and aggregate consumption and established that there is no positive relationship between the examined variables. In the same way, [17] have made an attempt in their study to analyze the impact of advertising expenditures on aggregate consumption on the ground of Houtakker-Taylor model and found that advertising 
expenditure influences aggregate consumption and aggregate consumption influences advertising, hence; bi-directional casual relationship found between the two examined variables.

Over the last decade, [1] studied the effectiveness of advertising on the sales income and profitability of a particular food and beverage business firms in Nigeria. In his time series study, he found that advertising has no positive significant association with the sales of the chosen companies by using the OLS method. Whereas, the significant relationship between advertisement expenditures and the profitability of the Nigerian companies have been concluded. [12] have examined the impact of advertising expenditures on turnover of Brewery Nigerian companies by using both the primary and secondary data and the analysis has been carried out through the OLS method. Their study concludes that advertising is a dominant determinant of the company turnover whether taken individually or in mixture with other relevant factors.

Another research study conducted by [11] has tried to study the long run relationship between advertisement expenditures and sales revenue using the co-integration methodology and found that there is a strong positive co-integrating relationship exists between advertising and sales revenue. Another study on the same ground conducted by [10] established that advertising expenditures and sales revenue are co-integrated of the same order. The outcomes showed that the casual relationship between the two mentioned variables is bi-directional.

[5] has tried to study the impact of advertising on sales for the food industry and found that advertising expenses has a positive and significant influence on foods sale for this particular industry and the given relationship between the said variables come out to be stable. [13] have attempted to study the effectiveness of advertising expenses on sales volume by means of the bivariate Vector Autoregression (VAR) model and founded that one time raise in advertising spending leads to improve in orange sales with a one month lag. It was also established that the influence of advertising on sales of grape fruit is more instant and comparatively large. While investigating the link between advertising expenses and sales revenue of a company during the time of recession, [9] established a considerable relationship between advertising and sales, even after controlling some important factors, for example, past sales and its growth, organization size, and so on.
While on the macro level, [8] investigated the relationship between advertising expenses and consumption using the United States data on advertising, personal consumption and disposable personal income. The author has used unit root tests as well as co-integration tests to check the stationarity and the long run relationship, in that order. The analysis concludes the existence of co-integration among the examined variables, which confirms the incidence of long run equilibrium relationship. [16] estimated the effectiveness of advertising expenditures on sales revenue of small as well as large business firms, in addition to multinational corporations. This study demonstrated that advertising expenses has affected sales revenue, despite the fact that this effect was not the identical for all the local and multinational corporations.

If we deeply review the existing literature that were quoted during this study, we come to conclude that each study has examined the relationship between advertising expenditures and sales for different local or multinational organizations either they were on the small or large scale. Moreover, some studies have confirmed the positive and significant relationship between the mentioned variables, while other studies rejected the same findings. But one thing must be realized that no one study has tried to attempt the influence of operating and financial expenses on sales revenue in Pakistan or outside the country. For that reason, this study is an attempt to fulfill the serious gap in the literature on the same concern.

\section{Data Description, Presentation and Its Limitations}

The available dataset used in this study for the empirical investigation consists of the annual observations on sales, selling and distribution expenses and financial charges of the Fauji Fertilizer Company Limited over the period 2002-2015. The given dataset has been taken from the company's annual financial statements and accounts reported on the last day of the month of December every year. The explanatory variables of this study are reported in terms of the cost expenditures. In order to make the analysis simple, the selling and distribution expenses have been proxy by operating expenses and similarly, the finance charges have been proxy by financial cost. In table 1 below, the detailed explanation of each variable is given for further understanding.

Table 1. Sketch of All included Variables.

\begin{tabular}{lll}
\hline Variable Name & Amount & Component \\
\hline Sales & 10 billion rupees & $\begin{array}{l}\text { Sales Revenue } \\
\text { Product transportation, salaries, wages, rents, taxes, sales promotion and advertisement, } \\
\text { Operating expenses }\end{array}$ \\
$\begin{array}{ll}\text { communication, depreciation, warehousing expenses, establishment and other expenses, etc. } \\
\text { Interest, long term loans, mark up on short run finances, bank charges, interest on workers profit } \\
\text { participation funds, etc. }\end{array}$ \\
\hline
\end{tabular}

Source: Financial Reports \& Accounts (2002-2015).

The dataset on the mentioned variables have been collected from the different financial records covering the 2002-2015 periods. Table 2 reports the numerical information on all the included variables for an empirical investigation over the mentioned time span. 
Table 2. Annual Reports and Accounts.

\begin{tabular}{llll}
\hline Year & Sales (Rs, 000's) & $\begin{array}{l}\text { Operating Cost } \\
\text { (Rs, 000's) }\end{array}$ & $\begin{array}{l}\text { Financial charges } \\
\text { (Rs, 000's) }\end{array}$ \\
\hline 2002 & $16,786,699$ & $1,457,797$ & 668,213 \\
2003 & $21,034,629$ & $1,851,170$ & 520,213 \\
2004 & $21,027,030$ & $2,788,791$ & 457,766 \\
2005 & $25,481,121$ & $3,744,096$ & 585,816 \\
2006 & $44,680,986$ & $4,268,699$ & 914,111 \\
2007 & $40,688,779$ & $3,618,791$ & $1,326,920$ \\
2008 & $57,433,698$ & $4,651,800$ & $3,246,550$ \\
2009 & $72,914,811$ & $5,810,394$ & $2,336,211$ \\
2010 & $88,154,698$ & $7,286,329$ & $2,001,355$ \\
2011 & $111,111,913$ & $7,731,516$ & $1,824,471$ \\
2012 & $122,251,581$ & $9,224,547$ & $2,691,660$ \\
2013 & $75,977,433$ & $6,237,555$ & $1,373,425$ \\
2014 & $84,013,999$ & $6,617,040$ & $2,149,262$ \\
2015 & $57,340,258$ & $6,967,239$ & $2,455,182$ \\
\hline
\end{tabular}

Source: Financial Reports \& Accounts (2002-2015)

\section{(c) Data Limitation}

We have taken the time series data for analysis and for estimation purposes in this study. And we know that the time series data carries the problem of non-stationarity which, in turn, incurs other problems in the analysis leading to the spurious results. That is the reason; the first step in the time series study is to check the stationarity in the dataset through the different test types, for instance, the Augmented Dickey-Fuller (ADF) test, the Phillips-Perron (PP), the Dickey-Fuller GLS (ERS), and so forth.

But to the check the stationaity in the data, we need a large sample size time series consists of at least 30 years. Unluckily, we are hereby restricted with only 14 year dataset due to the non-availability of large sample size for the particular company. Therefore, we cannot apply the above mentioned unit root tests for checking the stationarity. To solve the problem, we are taking a hidden assumption concerning the data that the data is stationary at levels which have been taken by many authors in their respective studies. If a series is stationary, its mean plus variance does not change notwithstanding at what point in time we determine them. That is, mean plus variance are time invariant under the presence of stationary time series. So, we can use the OLS results for finding the long-run relationship between the pairs of variables. The OLS results are reported in table 6 in details.

For the validity of the OLS results, different diagnostic tests were applied such as, Breusch-Godfrey Serial Correlation LM test, ARCH test, Jarque-Bera test and Ramsey RESET test for checking out the autocorrelation, heterescedasticity, normality assumption and misspecification of the model, respectively.

Table 3. Outcomes of Different Diagnostic Tests.

\begin{tabular}{|c|c|c|c|c|c|}
\hline Test Name & Problem & Obs* $\mathbf{R}^{2}$ & p-value & Decision & Outcome \\
\hline BG test & Autocorrelation & 0.3638 & $54.64 \%$ & Don't reject Null & No Autocorrelation \\
\hline $\mathrm{ARCH}$ test & Heteroscedasticity & 0.1560 & $69.29 \%$ & Don't reject Null & No Hetero \\
\hline $\mathrm{J}-\mathrm{B}$ test & Normality & $0.1168 *$ & $94.33 \%$ & Don't reject Null & Normal distribution \\
\hline Ramsey's RESET test & Misspecification & $3.0669 * *$ & $11.05 \%$ & Don't reject Null & Well-specified model \\
\hline
\end{tabular}

Note: Each Observed $\mathrm{R}^{2}$ value has been rounded-off to four decimal places.

* denotes the Jarque-Bera statistic value $\quad * *$ denotes the $\mathrm{F}$-statistic value

Source: Author's Computation (2017)

The table 3 above displays the outcomes of different diagnostic tests that were performed to check out some special econometric problems arose due to the violation of the assumptions of the model. The results of the Breusch-Godfrey test confirms that the model does not have autocorrelation or serial correlation issue as the probability value of observed $\mathrm{R}$-squared is greater than $5 \%$, hence we reject the alternative hypothesis by accepting the null; meaning that the residuals are not serially correlated with their lagged values.

The ARCH model assumes that there should not be heteroscedasticity in the residual. The verdicts of the ARCH test show that the probability value, here is 0.6929 , is more than $5 \%$, meaning that we can't reject our null hypothesis rather we accept it, and therefore; the results confirm that this model doesn't have the problem of heteroscedasticity. Next, the Jarque-Bera statistic would be performed to test whether the residuals follow a normal distribution or not, and from the results; this statistic stands at 0.1168 while its corresponding p-value is $0.9433(94.33 \%)$. Since the probability value is greater than $5 \%$, so we accept our null hypothesis that population residual is normally distributed which fulfills the assumption of a good regression line. Finally, to check whether our selected model is well specified or not, we need to have conducted the Ramsey's RESET test for this purpose. The corresponding $\mathrm{p}$-value for this stability diagnostic test is 0.1105 (or $11.05 \%$ ) which is greater than $5 \%$, confirming that we cannot reject our null hypothesis, consequently; no science of misspecification was found.

From these diagnostic tests, we come to conclude that our model satisfy all those assumptions which a researcher needs to consider in his account before going for the estimation. The results also reveal the fact that the selected model is well specified and there is no autocorrelation, no heteroscedasticity and no normality issue, thus; the OLS results (presented in table 6) are valid for inferences and confidently we would go for the policy recommendations.

(d) Testing Linear Restrictions

One of the characteristics of a good regression model is that explanatory variables should be jointly significant to influence explained variable (sales revenue). For this reason, the F-test would be performed. If the probability value of the F-statistic is less than 0.05 (or 5\%) we can reject the null and accept the alternative hypothesis. If we can reject the null hypothesis, it means that both the explanatory variables $\left(O E_{t}\right.$ and $\left.F C_{t}\right)$ jointly can influence explained variable $\left(\mathrm{Y}_{\mathrm{t}}\right)$.

Null hypothesis $=\mathrm{H}_{0}: \beta_{1}=\beta_{2}=0$ 
Alternative hypothesis $=\mathrm{H}_{1}$ : Not all $\beta$ 's are simultaneously equal to zero

Note that here $\alpha$ (the intercept term) is dropped as it is not connected with any explanatory variable in the model. Table 4 below displays the outcomes of this coefficient restrictions test.

Table 4. Outcomes of the Wald Test.

\begin{tabular}{|c|c|c|c|}
\hline \multicolumn{4}{|c|}{$H_{0}: C(2)=C(3)=0$} \\
\hline Test Statistic & Value & $\begin{array}{l}\text { Degree of } \\
\text { freedom }\end{array}$ & $\begin{array}{l}\text { Probability } \\
\text { (p-value) }\end{array}$ \\
\hline F-statistic & 147.3577 & $(2,11)$ & 0.0000 \\
\hline Chi-square & 294.7153 & 2 & 0.0000 \\
\hline
\end{tabular}

Source: Author's Computation (2017)

From the table 4 above, we glimpse that the corresponding probability value of the F-statistic is less than 5 percent (here $0.00 \%$ ), we reject our null hypothesis rather we accept the alternative hypothesis. More to the point, it means that both the explanatory variables can jointly influence sales in the population. Consequently, we should not drop the operating expenses or financial expenses variable from the model.

\section{Methodology and Estimation Technique}

To empirically explore the impact of operating and finance costs on sales, the standard multiple regression analysis has been suggested. The reason is, such analysis helps to determine whether there is any relationship between the explained and the explanatory variables. Similarly, such analysis helps to estimate coefficients of the model as well as to test the null hypotheses that are formulated in the present study.

In such analysis, three variables are taken into account for the empirical investigation in which sales are the dependent variable, while operating and finance costs are the independent variables.

The general functional form of the model is presented as follows:

$$
\text { Sales }=f(\text { operating expenses, finance cost })
$$

Symbolically,

$$
Y_{t}=f\left(O E_{t}, F C_{t}\right)
$$

Econometrically, the selected model can then be written as follows:

$$
Y_{t}=\alpha+\beta_{1} O E_{t}+\beta_{2} F C_{t}+\epsilon_{t}
$$

Where:

$Y_{t}=$ Sales at period $t$

$O E_{t}=$ Operating expenses at period $t$

$F C_{t}=$ Finance cost at period $t$

$\alpha=$ Constant term/vertical intercept

$\beta_{1}-\beta_{2}=$ Regression coefficients/slope parameters

$\epsilon=$ Stochastic disturbance term

\section{$t=2002-2015$}

Here in the regression model, the intercept $(\alpha)$ yields the value of sales when both operating and financial expenses are absolutely zero. Alternatively, $\beta_{1}$ and $\beta_{2}$, the slope coefficients, measures the change in sales revenue caused by a unit change of operating expenses and finance cost, correspondingly. More specifically, $\beta_{1}$ estimates the change in turnover or sales caused by a unit change in operating expenditures, while holding the effect of other expenditures constant. That is, $\beta_{1}=\frac{\Delta Y_{t}}{\Delta O E_{t}} / \overline{F C_{t}}$. Likewise, $\beta_{2}$ estimates the change in turnover caused by a unit change in financial expenditures, while keeping operating expenditures constant. That is, $\beta_{2}=\frac{\Delta Y_{t}}{\Delta F C_{t}} / \overline{O E_{t}}$. Furthermore, we expect that both $\beta_{1}$ and $\beta_{2}$ are positive, meaning that the company can enlarge its sales by rising its expenses for operating and finance.

To estimate the model in equation (3), the Ordinary Least Square (OLS) method can be applied. A time period of fourteen years was taken for this research covering the range from 2002 to 2015 , based on the condition of the availability of data.

The proposed model enables us to catch a more comprehensive picture of the variables and establish the significance of explanatory variables individually as well as jointly on the explained variable. The econometric analysis was carried out with the use of EViews software, which is, by default, made for the time series data analysis.

\section{Empirical Results}

\section{(e) Correlation Analysis}

While dealing with the multiple regression analysis, one of the main assumptions is that there is no perfect linear relationship between or among the explanatory variables in the model; otherwise the regression model cannot be estimated in the presence of perfect multi-collinearity. For such a reason, a correlation matrix can be obtained which will reveal the strength of the relationship between different pairs of variables included in the model.

Table 5. Outcomes of the Correlation Matrix.

\begin{tabular}{llll}
\hline Variables & Y & OE & FC \\
\hline Y & 1.000 & 0.980 & 0.750 \\
OE & 0.980 & 1.000 & 0.724 \\
FC & 0.750 & 0.724 & 1.000 \\
\hline
\end{tabular}

Note: Each value has been rounded-off to three decimal places. Source: Author's Computation (2017)

Table 5 reports that all the variables are positively correlated with each other. Though, it can be depicted that the sales are highly correlated with the operating expenditures of the company.

(f) OLS Results for FFC

By regressing the company's sales $(\mathrm{Y})$ on its expenses for operating $\left(\mathrm{X}_{1}\right)$ and finance $\left(\mathrm{X}_{2}\right)$ using the collected data in table 6 , we yield the expected value of parameter estimates. Both the coefficients of explanatory variables have a positive sign. This means that an increase in the operating and financial 
expenses have an increase in sales of the company in a result. The estimated regression equation is as follows:

$$
\begin{aligned}
& \hat{Y}_{t}=-13957625+13.7241 X_{1 t}+3.2177 X_{2 t} \\
& \text { t-statistic }
\end{aligned}
$$

Table 6. OLS Regression Results for FFC.

\begin{tabular}{lllll}
\hline \multicolumn{4}{l}{ Dependent Variable: $\mathbf{Y}$} \\
\hline \multicolumn{4}{l}{ Method: Least Square } \\
\hline \multicolumn{4}{l}{ Sample: 2002-2015 } \\
\hline Variable & Coefficient & $\begin{array}{l}\text { Standard } \\
\text { Error }\end{array}$ & t-statistic & p-value \\
\hline $\mathrm{C}$ & -13957625 & 4829773 & -2.8899 & 0.0147 \\
$\mathrm{X} 1$ & 13.7241 & 1.2378 & 11.0879 & 0.0000 \\
$\mathrm{X} 2$ & 3.2177 & 3.1732 & 1.0140 & 0.3324 \\
\hline
\end{tabular}

$\mathrm{R}^{2}$

Adj. $\mathrm{R}^{2} \quad 0.9575$

F-Statistic $\quad 147.3577$

Prob. (F-statistic) 0.0000

Note: Each value has been rounded-off to four decimal places.

Source: Author's Computation (2017)

The interpretations of these results suggest that for each one million rupee increase in expenses of operating and finance, the sales revenue of the company increase by 13.72 million rupees and 3.21 million rupees, correspondingly. Moreover, the probability value of $\mathrm{X}_{1}$ variable is $0.00 \%$, which is less than $5 \%$, meaning that this $X_{1}$ is a highly significant variable to influence the dependent variable, which are sales. Similarly, the $\mathrm{p}$-value of $\mathrm{X}_{2}$ variable is $33.24 \%$, which is more than $5 \%$, showing that this $\mathrm{X}_{2}$ is not significant variable to influence the dependent variable.

The diagnostic test, such as $\mathrm{R}^{2}$, showed that sales in the company are explained by about $96.40 \%$ jointly by the two explanatory variables. The rest $3.60 \%$ proportion of variation in sales can be explained by other variables rather than $X_{1}$ and $\mathrm{X}_{2}$ that are not included in the model. Similarly, the value of Adjusted $\mathrm{R}^{2}$ is 0.9575 which means that the total variation in dependent variable explained by the regression is about $96 \%$. At last, the corresponding p-value of the F-statistic is $0.00 \%$, which is less than $5 \%$, confirming that both explanatory variables jointly can influence the sales of the company.

(g) Tests of Hypotheses

There are two hypotheses tested empirically during the analysis of this research study.

Hypothesis 1:

$H_{01}$ : There is no substantial expansion in sales of the FFC as a result of the administrative and distribution (or operating) expenditures.

Hypothesis 2:

$H_{02}$ : There is no significant improvement in sales of the FFC as a result of the finance charges over the period.

In evaluating the linkage between operating expenses and sales and finance charges and sales revenue for the FFC in Pakistan and in particular test the above hypotheses, the OLS method is applied via the time series dataset covering the 2002-2015 periods using sales as explained variable, whereasthe operating expenses and financial charges are the explanatory variables, in that order. The parameter estimates for both the hypotheses are given in table 7 .

Table 7. Tested Hypothesis Results.

\begin{tabular}{llllll}
\hline Variable & $\boldsymbol{\beta}$ (beta value) & $\mathbf{R}^{\mathbf{2}}$ & Adj. $\mathbf{R}^{2}$ & F-statistic & D-W stat. \\
\hline $\mathrm{X}_{1}$ & 14.63 & 0.96 & 0.96 & 292.90 & 1.44 \\
$\mathrm{X}_{2}$ & 28.69 & 0.56 & 0.53 & 15.39 & 0.80 \\
\hline
\end{tabular}

Note: Each value has been rounded-off to two decimal places. Source: Author's Computation (2017)

From the table 7 above, both the coefficients appear with a positive sign having values 14.63 and 28.69 correspondingly for the FFC, and the beta value for $\mathrm{X}_{2}$ variable is greater than the remaining one. Though, the predictive power of operating expenses on sales is $96 \%$ and the predictive power of financial charges on sales is $56 \%$ for the FFC. The verdicts reveal the fact that operating expenses as well as financial charges have significant impact on sales volume of the FFC in Pakistan. Therefore, both the null hypothesis is straightforwardly rejected for the recognition of alternative propositions in this study.

\section{(h) Elasticity Measurements}

The concept of elasticity is very significant in the field of Economics not only just for the sake of evaluating the consumer behavior, the producer behavior, etc. but also have an important role in policy implications for any individual entity. For instance, the analysis of advertising expenditures on the consumer demands for particular goods of a company.

It quantitatively measures the responsiveness of one variable caused by the change in another variable. More to the point, it hereby measures the responsiveness of the sales revenue due to a percent change in the operating expenses of the company. Similarly, it measures the responsiveness of sales volume due to a one percent change in the financial charges of the FFC. The nature and strength of the responsiveness of the interest variable due to a one percent change in another variable can be depicted from the sign and numerical value of the elasticity measurement, respectively.

Mathematically,

$$
\text { Elasticity }(\varepsilon)=\frac{\% \text { age change in sales revenue }}{\% \text { age change in operating expenses }}=\frac{\% \Delta Y}{\% \triangle O E}
$$

Similarly,

$$
\text { Elasticity }(\varepsilon)=\frac{\% \text { age change in sales revenue }}{\% \text { age change in financial expenses }}=\frac{\% \Delta Y}{\% \Delta F E}
$$

The calculated values of the above equations for elasticitiesare reported in table 8 as follows.

Table 8. Results of Scaled Coefficients (Elasticity Coefficients).

\begin{tabular}{lllll}
\hline Variable & Coefficient & $\begin{array}{l}\text { Standardized } \\
\text { Coefficient }\end{array}$ & $\begin{array}{l}\text { Elasticity } \\
\text { at Means }\end{array}$ & Conclusion \\
\hline $\mathrm{C}$ & -13957625 & N/A & -0.2249 & - \\
$\mathrm{X}_{1}$ & 13.7241 & 0.9193 & 1.1413 & Elastic \\
$\mathrm{X}_{2}$ & 3.2177 & 0.0841 & 0.0836 & Inelastic \\
\hline
\end{tabular}

Note: Each value has been rounded-off to four decimal places. Source: Author's Computation (2017)

From the table 8 above, we can see that both the calculated 
values of elasticities have a positive sign, demonstrating that the sales revenue shows a positive response in a result due to a unit percent change in any of the independent variable. As the calculated value of the elasticity for $\mathrm{X}_{1}$ variable, which is 1.14 , is greater than unity, we call it the elastic variable; which means that the sales revenue responds greater than proportionally to changes in operating expenses. On the other hand, the elasticity coefficient of $X_{2}$ variable, which is 0.084 , is less than unity, we call it the inelastic variable; meaning that the sales revenue changes below proportionally in a result of changes in the financial expenses.

\section{(i) Granger Causality Test}

Causality is one of the important concepts used in time series econometrics, which is rather different to the daily use concept; as it means more to the capability of one variable to envisage the second variable. In order to check out the pair wise causality between any two variables, Granger (1969) presented a quite easy test, known as the Granger causality test. According to this test, a variable $Z_{t}$ is supposed to Granger cause $Y_{t}$ if the $Y_{t}$ can be foresees with immense precision by taking the past observations of the $Z_{t}$ variable rather than not using such precedent values, while keeping all the remaining terms as constant and vice versa. More to the point, this concept deals whether current and past values of $Y_{t}$ facilitate to forecast future values of $Z_{t}$. In a two variables case, say $Z_{t}$ and $Y_{t}$, the Granger causality can be written as:

$$
\begin{aligned}
& Z_{t}=\alpha_{1}+\beta_{i} Y_{t-i}+\gamma_{t} Z_{t-j}+\varepsilon_{1 t} \\
& Z_{t}=\alpha_{2}+\varphi_{i} Y_{t-i}+\omega_{t} Z_{t-j}+\varepsilon_{2 t}
\end{aligned}
$$

In this section of the time series analysis, we are going to test the causality between any two variables by setting the null hypothesis as follows.

Hypothesis 3:

$H_{03}$ : There is no casual relationship between any two variables in the whole system of the model.

Results of the pair wise granger causality test for different lags are given below in table 9 .

\begin{tabular}{|c|c|c|c|c|}
\hline Direction of Causality & p-value & Lags & Decision & Outcome \\
\hline $\mathrm{X}_{1}>\mathrm{Y}$ & $56.94 \%$ & 2 & Do not reject Null & $\mathrm{X}_{1}$ does not cause $\mathrm{Y}$ \\
\hline$Y>X_{1}$ & $56.30 \%$ & 2 & Do not reject Null & $Y$ does not cause $X_{1}$ \\
\hline$X_{2}>Y$ & $31.07 \%$ & 2 & Do not reject Null & $\mathrm{X}_{2}$ does not cause $\mathrm{Y}$ \\
\hline$Y>X_{2}$ & $82.58 \%$ & 2 & Do not reject Null & $Y$ does not cause $X_{2}$ \\
\hline $\mathrm{X}_{2}>\mathrm{X}_{1}$ & $26.61 \%$ & 2 & Do not reject Null & $\mathrm{X}_{2}$ does not cause $\mathrm{X}_{1}$ \\
\hline $\mathrm{X}_{1}>\mathrm{X}_{2}$ & $26.46 \%$ & 2 & Do not reject Null & $\mathrm{X}_{1}$ does not cause $\mathrm{X}_{2}$ \\
\hline $\mathrm{X}_{1}>\mathrm{Y}$ & $90.51 \%$ & 4 & Do not reject Null & $\mathrm{X}_{1}$ does not cause $\mathrm{Y}$ \\
\hline $\mathrm{Y}>\mathrm{X}_{1}$ & $77.17 \%$ & 4 & Do not reject Null & $Y$ does not cause $X_{1}$ \\
\hline $\mathrm{X}_{2}>\mathrm{Y}$ & $37.16 \%$ & 4 & Do not reject Null & $\mathrm{X}_{2}$ does not cause $\mathrm{Y}$ \\
\hline $\mathrm{Y}>\mathrm{X}_{2}$ & $92.60 \%$ & 4 & Do not reject Null & $Y$ does not cause $X_{2}$ \\
\hline $\mathrm{X}_{2}>\mathrm{X}_{1}$ & $08.79 \%$ & 4 & Do not reject Null & $\mathrm{X}_{2}$ does not cause $\mathrm{X}_{1}$ \\
\hline$X_{1}>X_{2}$ & $38.28 \%$ & 4 & Do not reject Null & $\mathrm{X}_{1}$ does not cause $\mathrm{X}_{2}$ \\
\hline
\end{tabular}

Table 9. Pair wise Granger Causality Test.

Source: Author's Computation (2017)

The results in table 9 above reveals the fact that the probability value for each pairwise causality is more than $5 \%$ for different lags selection, meaning that we can't reject null hypothesis rather we accept it. That is, the verdicts sturdily confirmthe fact that there is no casual relationship between any two variables in the whole system of the model. For example, the operating expenses doesn't granger cause sales revenue, and the same context can be applied to all other relationships. Hence, there is not any directional causality for a set of any two variables in the whole system.

\section{Conclusion and Recommendations}

In this research work, we considered the linear regression model to inspect the impact of operating and financial expenses on sales revenue of the Fauji Fertilizer Company Limited in Pakistan using a time series dataset covering the period 2002-2015. The OLS method has been used to estimate coefficients of the model subject to the hidden assumption that all the variables included in the model are stationary at level. Over this time series analysis, some results were documented by means of empirical implications. First, sales are highly correlated with the operating expenditures of the company. Second, the operating expenses variable ishighly significant to influence the sales volume. Third, the predictive strength of the operating expenses on sales is more than the predictive influence of finance charges on sales for the FFC. Fourth, the elasticity for operating expenses is more elastic than for the financial charges. Last of all, there is no casual relationship between any sets of variables.

On the ground ofthe results of this work, we advocate some policy steps to the company in order to boost its production level. As the operating expenses are significant to explain sales revenue, then the company must need to increase its advertising expenditures so as to increase sales of the company. Due to the significant impact of the ongoing expenses on sales, the company must encourage its expenses on sales promotion, technology, new infrastructure, and on running advertisement to facilitate the emerging needs of the consumers. Additionally, the company needs to decrease its financial charges to avoid further losses and is advised to spend the same amount on the administrative and distribution side of the organization. The significant and elastic nature of the operating expenses on sales will boost up the company in 
future by revising the expense structure of the company.

\section{References}

[1] Abdullahi, D. (2015), "Effect of Advertising on the Sales Revenue and Profitability of selected Food and Beverages firms in Nigeria", A Research Thesis submitted to the School of Post Graduate Studies, Ahmadu Bello University, Zaria.

[2] Akanbi, P. A., Adeyeye, T. C. (2011), "The Association between Advertising and Sales Volume: A Case Study of Nigerian Bottling Company Plc", Journal of Emerging Trends in Economics and Management Sciences (JETEMS), 2 (2): 117-123.

[3] Cunningham, B. M., Nikolai, L. A. \& Bazley, J. D. (2002), "Accounting (Information for Business Decisions), $2^{\text {nd }}$ Edition, Columbia: Thomason Learning.

[4] Ekelund, R. B. \& William, P. G. (1969), “A Reconsideration of Advertising Expenditures, Aggregate Demand and Stabilization", Quarterly Review of Economics and Business (summer), pp. 71-77.

[5] Elliot, C. (2001), "A Cointegrating Analysis of Advertisement and Sales Data", Review of Industrial Organization, Vol. 18, pp. 417-426.

[6] FFC (2016), "Shaping a Sustainable Future", Fauji Fertilizer Company Limited Annual Report 2016, the FFC, pp. 1-232.

[7] Granger, C. W. J. (1969), "Investigating Casual Relations by Econometric Models and Cross-spectral Methods", Econometrica, Vol. 37 (3), pp. 424-438.

[8] Guo, Chiquan (2003), "Cointegrting Analysis of Advertising Consumption Relationship", Journal of the Academy of Business and Economics, February, Obtained through the internet: www.findarticles.com, [Accessed on $3^{\text {rd }}$ February, 2008].
[9] Kamber, T. (2002), "The Brand Manager Dilemma: Understanding How Advertising Expenditures Affect Sales growth during the recession", The Journal of Brand Management, Vol. 10 (2), pp. 106-120.

[10] Lee, J., Shin, B. S. \& In Chung (1996), "Causality between Advertising and Sales: New Evidence from Cointegration", Applied Economic Letters, Vol. 3, pp. 299-301.

[11] Leong, S. M., Outiaris, S. \& Franke, G. R. (1996), "Estimating Long term Effects of Advertising on Sales: A Cointegrating Perspective", Journal of Marketing Communication, Vol. 2 (2), pp. 111-122.

[12] Olaniyi, T. A., Salman, R. T. \& Adebayo, S. A. (2013), "Impact of Advertising on Turnover of Brewery Companies in Nigeria", International Journal of Science and Research (IJSR), 2 (6): 2319-7064.

[13] Pagan, J., Sethi, S. \&Soydemir, G. A. (2001), "The Impact of Promotion/Advertising Expenditures on Citrus Sales", Applied Economic Letters, Vol. 8 (10), pp. 659-663.

[14] Pandey, I. M. (2000), Financial Management, New Delhi, Vikas.

[15] PSX (2014), “Top 25 Companies Awards 2014-2015”, Pakistan Stock Exchange Limited, the PSX, pp. 1-43.

[16] Sundarsan, P. K. (2007), "Evaluating Effectiveness of Advertising on Sales: A Study using Firm Level Data", ICFAI Journal of Managerial Economics, Vol. V (1), pp. 54-62.

[17] Taylor, L. D. \& Daniel, W. (1972), “Advertising and Aggregate Consumption Function", American Economic Review, Vol. LX11 (4), pp. 642-655.

[18] Verdon, W. A., Campell, R. McConnel. \& Theodore, W. R. (1968), "Advertising Expenditures as an Economic Stabilizer: 1945-64", Quarterly Review of Economics and Business (Spring), pp. 7-18. 